\title{
EL GOBIERNO EN LOS PROGRAMAS DE GOBIERNO
}

Francisco Javier Ibisate, S.J.

\section{I.- Introducción : la fase preelectoral}

Es un dato orientador que en las encuestas de opinión pública una elevada mayoría de la población manifestara su deseo de votar y también que una mayoría relativa dejara entrever su indecisión por un determinado partido. Estos elevados porcentajes de opinión muestran que la ciudadanía ha tomado conciencia de que hay que buscar muchas nuevas soluciones a los muchos problemas permanentes, y al mismo tiempo que se halla en una fase de inquisición sobre la fracción política, en singular o en plural, que ofrezca mejores garantías de capacidad y de honestidad. Es aquí donde encajan los programas de gobierno, cuyo mérito estará en el análisis de los problemas permanentes y en las alternativas de solución planteadas.

Al igual que cualquier análisis de la realidad todo programa de gobierno debe obedecer ciertas normas del método científico. La primera norma es decir la verdad, no disimular ni falsificar la realidad, no restringirla a una parcela de dicha realidad. Los programas de gobierno tocan una realidad muy compleja en sí misma, hecha de múltiples componentes (políticos, económicos, legalesjurídicos, técnicos y sociales...); una realidad que aparece muy diferente de acuerdo a la posición político-social de quien analiza la verdad. Un programa de gobierno se hace, en primera instancia, para iluminar al elector sobre una secuencia de problemas nacionales, registrados de acuerdo a la importancia relativa que le da el 
mismo programador. Esta fase de los programas de gobierno sirve, no sólo para iluminar al elector sobre la existencia de un cúmulo de retos, carencias y problemas, sino para que el elector pondere si sus propios retos, carencias y problemas aparecen reflejados en tales programas de gobierno. También, cada grupo de electores leen la realidad de modo diferente y serán diferentes las esperanzas y las expectativas concretas.

Los partidos políticos tienen una doble característica. Que son y se definen como algo-partido, distinto de los otros partidos. Segundo, que buscan el poder. Hay que conciliar lo primero con lo segundo. Como "partido", representantes de determinada fracción, buscarán intencionalmente lo que más favorezca a sus representados, de quienes esperan el voto. Como instituciones que buscan el poder tienen que captar la benevolencia de otra amplia base de la población. Esta ambivalencia lleva fácilmente a una dualidad de promesas y propuestas: las que realmente se harán a favor del sector representado y las que quedarán en la vía muerta si llegan al poder. Como el papel aguanta todo es normal que los programas de gobierno, en su expresión escrita y sobre todo en su expansión verbal, se caractericen por la acumulación de promesas y propuestas.

La fase preelectoral se convierte así en una confrontación de técnicas de publicidad, cuyo éxito está fundamentalmente condicionado por la capacidad financiera para acaparar los mayores espacios en los medios de comunicación.

En esta lidia el partido en el poder cuenta con múltiples formas de canalizar fondos públicos a este fin, y al resto de partidos les queda el derecho de protestar. La publicidad política sabe que si los ciudadanos desean votar, desearán conocer las ofertas alternativas y por medio de radio y televisión se pueden visitar repetidas veces los cantones más alejados. Expertos en psicología emocional saben que las expectativas de amplios sectores se nutren con el martilleo de repetidas imágines, consignas subliminales, acumulación de promesas y también volviendo a arañar cicatrices aún abiertas del pasado. La tergiversación de la realidad y las medias verdades sirven a disfrazar las grandes mentiras; también se tocan las teclas nacionalistas cuando la verdad llega desde fuera. La fase preelectoral se parece a la confrontación oligopólica con guerra de 
precios. Por desgracia, en nuestro caso no se puede hablar de oligopolio, unos pocos, sino de polipolio diferenciado, donde la multiplicidad de partidos prometen el mismo bienestar para todos, sólo que a su manera. La comparación situaría más bien al elector en el centro de una bolsa de valores donde aturden sus oídos con la cotización de los más diversos títulos-políticos.

Para contrarrestrar la publicidad emocional es necesario recurrir a la historia. La historia es un pasado real y la mejor premisa para proyectar el futuro. Suele decirse que la historia juzgará a los hombres. Pero no conviene relegar este juicio al mediano-largo plazo cuando se trata de evaluar a los partidos políticos que ya tienen su historia. Sus programas de gobierno, sus múltiples promesas, su sensibilidad social hay que leerlos desde su historia pasada y no desde la publicidad artificial. La publicidad promete, la historia demuestra la intención y la capacidad de hacer lo prometido. Los partidos que cuentan con una historia pasada tienen una ventaja relativa: pueden espigar y seleccionar algunos hechos lúcidos del pasado. Pero también tienen un pesado gravamen en su contra: lo que prometieron y nunca hicieron, lo que el viento se llevó.

Si a las elecciones de 1994 les están llamando las elecciones del siglo es porque de ellas se espera algo que no se logró en el pasado; la esperanza, la última propiedad privada de los pobres, vuelve a renacer cada cinco años. Los partidos con historia pasada lo saben y por ello se sirven de la publicidad para acolchonar las esquinas dolientes de su historia. Hay un hilo conductor o un común denominador en estas historias pasadas; cada partido que sube al poder estrena sus primeras energías en acusar a su predecesor de múltiples hechos de corrupción; para no romper la tradición también bajo el actual gobierno se creó una comisión a tal fin, pero todavía no florea la cosecha. A modo de fuegos artificiales nos hemos acostumbrado a escuchar: "se harán investigaciones exhaustivas". Vuelve a ser verdad el lema de cambiar para mejorar.

Un programa de gobierno es un programa multifacético que debe integrar la cara económica con la estructuración política, jurídica e institucional de la convivencia social. En anterior publicación citábamos el programa económico de consenso de CENITEC, cuyos primeros lineamientos se refieren a esta integración de las 
esferas civiles. " El primero, referido a la interrelación de los órdenes político, económico, social, jurídico, parte de la premisa de que la realidad es única e indisoluble, y por tanto no se pueden separar los avances en la dimensión económica del progreso que tiene que darse en los otros planos. En base a esta característica subrayamos la incompatibilidad de un sistema económico basado en la economía social de mercado con un sistema político autoritario y antidemocrático". El comentario añadía :" el desarrollo en democracia no puede surgir de la simple adición de políticas económicas neoliberales con políticas sociales compensatorias". (Realidad Económico-Social; No, 35, 1993; p.497).

Recurriendo a la historia contemporánea, sin entrar en las litigadas fronteras del cuanto sí y cuanto no se ha cumplido de los acuerdos de paz, nos topámos con el impenetrable muro que se ha levantado frente al informe de la Comisión de la Verdad. Este sí es el muro de la vergüenza. A las piezas negras del gran mosaico de la pobreza se suman las más duras resistencias a descubrir y enjuiciar la impunidad institucional. Sin educación no hay nación, y la primera educación es la verdad. La ley de amnistía, presentada como la consigna cívica del perdón y olvido se ha convertido en el más lamentable olvido del perdón. Al negarse a enjuiciar la historia y a los que hacen la historia, las conciencias no cambian y no cambiará la historia. Una vez más los amnistiados de siempre son los que practicaron el mal y la injusticia en sus más negras variedades; con la ley de amnistía se les priva de la posibilidad de poder tener remordimiento de conciencia. A las víctimas se les pide que perdonen y olviden, que de este perdón-olvido brotará un "derrame de bondad". Parecería que en el modelo político y en el modelo económico la teoría del derrame les toca aguantarla a los más pobres.

Más que difícil es imposible llegar a hacer una lectura objetiva de los programas de gobierno si no logramos un cierto acuerdo sobre las estructuras subyacentes y determinantes de nuestros hechos históricos. El problema es tanto mayor por cuanto nos negamos a aceptar la existencia de estas estructuras. Uno de los aportes más importantes del informe de la Comisión de la Verdad es su interpretación de la "fenomenología de la violencia", que conduce a la culpabilidad institucional. Si los comisionados analizan, desde 
un enfoque jurídico, la estructura ruinosa de nuestra administración de justicia, es previsible - en razón de la teoría de los vasos comunicantes - que en la misma sociedad coexistan similares estructuras en el ordenamiento económico-social. Para mostrarlo comenzamos por citar el referido párrafo de la Comisión de la Verdad.

"Un aserto universalmente mantenido establece que el sujeto de toda situación delicuencial es el ser humano, único capaz de voliciones y por tanto de decisiones de voluntad; delinquen los individuos y no las instituciones creadas por ellos. En consecuencia es a aquellos y no a éstas a quienes han de aplicarse las penas respectivas establecidas por las leyes. Sin embargo, en ciertos contextos se presentan hechos repetitivos en el tiempo y en el espacio que parecerían rectificar la premisa anterior. Pueden darse, en efecto, reiteraciones delicuenciales en las que actúen como protagonistas dentro de la misma institución, con analogía inequívoca, individualidades diferentes, más allá del signo político de los gobiernos y de quienes toman las decisiones; lo cual da campo para pensar que las instituciones sí delinquen, dados los mismos comportamientos a manera de constante. Con mayor razón si a la claridad de las imputaciones se sigue el encubrimiento por parte de la institución a la que pertenecen los protagonistas implicados y el entorpecimiento institucional frente a las responsabilidades que se desprenden de las investigaciones. En tales circunstancias, es fácil sucumbir a la fuerza de las reiteraciones para señalar la culpabilidad institucional". (ECA; No, 533; marzo-1993; p.164). La Comisión de la Verdad, sin dar nombres, nos presenta moviéndose entre bambalinas al grupo de los "civiles influyentes"; estos son los vasos comunicantes que determinan el esqueleto de las estructuras económicas.

Muestra de que es difícil aceptar estas estructuras de impunidad es la apresurada ley de amnistía. La pregunta es si aquí hay fallo de memoria o de voluntad. El mismo Presidente que apoyó con su autoridad, y sin duda por presión de sus partidarios, esta ley dijo algo muy distinto en su discurso de Chapultepec. "Nos quedaríamos injustamente cortos si viéramos sólo hacia el pasado inmediato para medir de la magnitud de lo que ocurre en El Salvador. De un tiempo a esta parte, la crisis en que se vio envuelta 
la nación salvadoreña, en el último decenio, no surgió de la nada ni fue producto de voluntades aisladas. Esta crisis tan dolorosa y trágica tiene antiguas y profundas raíces sociales, políticas, económicas y culturales. En el pasado, una de las perniciosas vallas de nuestro esquema de vida nacional fue la inexistencia e insuficiencia de los espacios y mecanismos necesarios para permitir el libre juego de las ideas, el desenvolvimiento natural de los distintos proyectos políticos derivados de la libertad de pensamiento y de acción. En síntesis, la ausencia de un verdadero esquema democrático de vida...De cara al futuro, el Acuerdo de paz es un acto de plena libertad y perfectibilidad de todo un pueblo, cuyo sufrimiento y estoicismo le han dado un supremo derecho a las esperanza; esa esperanza en una vida más humana y más plena, sin exclusiones y privilegios, toma cuerpo en el Acuerdo de paz y por ello decimos que este Acuerdo es una plataforma de armonía para el presente y para el futuro"...(ECA; Nos. 519-520; enero-febrero 1992; p. 165).

Podríamos agregar el discurso del Secretario General de las Naciones Unidas, Dr. Boutros-Boutros Ghali (pp.153-156) o el de Shafik Handal, para entender mejor de qué estructuras se habla en Chapultepec: "La firma del Acuerdo de paz marca la culminación de una etapa decisiva en la larga y heroica lucha del pueblo salvadoreño por sus ideales de libertad, justicia, democracia, dignidad humana y progreso"...(pp. 156-157)

Parecería que los discursos se aplauden por cortesía y se olvidan con la misma rapidez cuando hay una resistencia congénita a aceptar su contenido. Con ello se distorsiona la historia, se crea un demiurgo culpable del mal y se liberan las propias conciencias de toda culpabilidad. El demiurgo que vino a torcer nuestra historia fue la década perdida de los 1980, el Estado prepotente, los subversivos, los otros. No nos detendríamos en este punto sino fuera $\tan$ maliciosa la repetida lectura que los documentos oficiales del gobierno-partido y de las hegemónicas gremiales privadas hacen de esa década. Los tres discursos citados nos dicen - sin alargarnos más - cuáles fueron las causas de la guerra civil. Pero una vez en guerra el "sector-privado" no sale con las manos limpias de culpa y corrupción.

Se dirá que el Estado les nacionalizó el sistema de exportaciones tradicionales; la verdad es que la adversa coyuntura interna- 
cional, la segunda sacudida de la recesión mundial, quebró y redujo al cincuenta por ciento el valor en dólares de nuestras exportaciones. Que esta fuera la causa fundamental lo seguimos resintiendo de 1989 a nuestros días, una vez reprivatizados los canales de su exportación; más aún la economía no encuentra ya base segura en tales exportaciones, superadas en los últimos años por las remesas familiares. Se dirá que el Estado nacionalizó su banca; la verdad es que el sector privado la descapitalizó con la patriótica fuga de capitales que, a lo largo de la década y con el reciclaje de los pobre-dólares, puso fuera del país un monto similar al de nuestra deuda externa. Se dirá que hubo mucha corrupción en la administración de los créditos; la verdad es que para que haya corrupción hacen falta dos: el que pide y el que concede, el que otorga y el que no devuelve. Al privatizar triunfalmente la banca se presenta como prueba de la corrupción los 2.300 millones de moras acumuladas; los dos tercios eran créditos irrecuperables o de difícil recuperación. Por una vez en la historia los diarios publicaron la lista de los grandes morosos; no se dan nombres, sino los títulos comerciales de las grandes empresas. En reconocimiento a estos méritos, a los nombres se les conceden puestos privilegiados en la administración del sistema privatizado.

Pero la ironía en clave mayor es que quienes aplaudieron y movilizaron la guerra como la única solución se rasgan las vestiduras ante los déficits fiscales, el gravamen de la deuda externa, los controles estatales. Cómo se puede aplaudir una guerra sin admitir el crecimiento de la deuda externa, del déficit fiscal, la destrucción del país y el superimperio del estamento militar?. Un triste derivado de esta postura belicista es el informe de la Comisión de la Verdad. Hacen la historia y luego la vituperan creando chivos expiatorios. $Y$ los mismos que se apresuraron por editar la ley de amnistía han querido hegemonizar el foro de Cultura para la Paz.

La fase preelectoral y post-electoral seguirá siendo una confrontación entre la publicidad y la historia. El agravante es que la poderosa publicidad puede mentir y enturbiar la lectura de la historia. Una historia que lógicamente la leen en forma muy diferente los de arriba y los de abajo. Esto explica el deseo de votar y la indecisión, más las trabas, del por quién votar. La falsa publicidad 
puede vencer pero no logra convencer y quinquenio tras quinquenio sigue engendrando sus propios adversarios. Es misión de los hombres de buena voluntad el ayudar a leer los programas de gobierno de las diversas fracciones políticas desde la arqueología histórica para gestar una nueva historia.

\section{IIo. LA ARMONIZACION DE UN PROGRAMA DE GOBIER- NO}

Desde los años de 1960 tenemos un historial de programas de desarrollo económico-social como eje central de los programas de gobierno. Esta modalidad respondía a una tradición occidental europea y latinoamericana. Cada plan de desarrollo responde a una filosofía o teoría del gobierno de turno. Por ejemplo, es bien distinto el enfoque y las medidas económicas que nos proponía el plan de desarrollo 1973-1977 de lo que fuera el siguiente plan de bienestar para todos, 1978.., inspirado en la doctrina de la seguridad nacional, que abortó inmediatamente por ilusorio, equivocado y porque estalló lo que tenía que estallar. El actual plan de desarrollo 1989-1994 se introduce con los principios filosóficos y los postulados económicos de una sociedad libre, identificada con la economía de mercado; tales principios y postulados fueron literalmente transferidos de la publicación que editara FUSADES en mayo de 1989.

Este breve recuento sirve a recordar que los programas de gobierno se reducían, como publicación representativa, a los correspondientes planes de desarrollo económico, con o sin el aditivo de social. Se daba por supuesto que existían otros poderes públicos, judicial, legislativo, militar, que tenían su propia normativa en cuanto poderes diferentes del ejecutivo y de su planificación económica. Los poderes públicos se concebían como complementarios y compensadores, propios de un Estado de Derecho e instituidos para vetar una dictadura omnipresente. La sociedad presentaba una imagen de democracia formal y de equilibrio en las funciones públicas. No es menester alargarse en recordar que la estructura de funcionamiento distaba mucho de su formalidad. Es aleccionador que, entre tantos documentos y voces criticas, la proclama de los jóvenes militares que dieron el golpe de estado, octubre de 1979, resaltaran la conjugación y confabulación de todos los 
poderes públicos para gestar, a modo de tandona, un gobierno que "ha violado los derechos humanos del conglomerado"...(Realidad Económico-Social; No 33; 1993; pp. 229-230).

Hoy día, finalizada la guerra y puestos en marcha los entrabados acuerdos de paz, es claro que un programa de gobierno no puede cantonarse a un plan de desarrollo económico y su correspondiente programa monetario, porque no sólo de pan malvive el hombre. Es tan obvia esta integración de los diversos órdenes civiles que las plataformas de los principales partidos contendientes integran las propuestas de acción política,legal, democrática, económica y social...Los "derechos humanos", con una u otra etimología, aparecen en el frontispicio de estas proclamas. Como el refrán dice que quien pega primero pega dos veces, el partido ARENA se adelantó a presentar su programa de gobierno nacional 1994-1999, detallando un largo índice de promesas y expectativas para la nueva sociedad. (La Prensa Gráfica; 30-mayo-93; pp. 25-28). En anterior comentario se decía que el Dr. A. Calderón Sol abandonaba el lema belicista "los arrollaremos", adoptando en esta proclama la táctica conciliatoria de "los arrullaremos" con una amplia cascada de promesas.

Lo que se quiere indicar es que esta plataforma de ARENA marca una pauta de integración de todas las esferas civiles, presentando un plan de gobierno y un plan de desarrollo económicosocial basados en unos principios por demás humanitarios. Esa primera página no ha servido tanto a un proceso de autocrítica y autoconversión, sino que ha dado pie a la crítica de las fracciones contendientes y a la contrapropuesta de similares principios, con otros contenidos. En realidad, los principios humanitarios vertidos en esta primera página de ARENA no encajan con su historia reciente, pero tienen el mérito de ser los principios inspiradores para quienes pretendan instituir la nueva sociedad. Los resumimos en frases sueltas: "La dignidad de la persona humana, creada a imagen y semejanza de Dios; la libertad, la justicia y el orden social; el derecho a la vida y a la propiedad; la educación y la salud como derechos fundamentales; la igualdad de oportunidades desde el inicio mismo de la vida; el bien común como fin de todos los esfuerzos; un sólida Estado de Derecho; desarrollo democrático en un proceso de paz..." Realidad Económico-Social; No.33; 1993; pp. 
356...) En la cita bibliográfica nos preguntábamos si la historia de ARENA se venía inspirando en tales principios humanitarios. Ahora queremos simplemente señalar que, de acuerdo a las demandas populares y a la creciente toma de conciencia de los derechos humanos, los programas de gobierno tienen que presentar respuestas integradas a los problemas integrados. La tarea del lector y del elector será hacer, con más razón que emoción, el análisis comparativo de las propuestas y de la historia.

Los programas de gobierno tienen, en principio, una doble finalidad: en primer lugar, buscan traducir las múltiples demandas de todos los estratos civiles,desde la infancia hasta la tercera edad y desde la cultura deportiva hasta la generación de empleo. Esto da la imagen de un supermercado de ofertas. En segundo lugar, los programas de gobierno servirían como agenda de trabajo para el partido electo, a realizar por todas y cada una de sus múltiples dependencias públicas. Es lógico que los programas de gobierno den esa impresión de supermercado de ofertas por cuanto cada grupos de electores, de acuerdo a su edad, condición social, profesión o modo de ganarse la vida, rebuscará una respuesta a sus propias expectativas. Esto puede explicar la amplitud de los programas de gobierno; no se quiere dejar en el tintero ninguna de las solicitudes emanadas de los acuerdos de paz, de las encuestas de opinión pública e incluso, sin nombrarlo, del informe de la Comisión de la Verdad. También difieren la estructuración de los acápites componentes y el estilo de redacción, más utópico o más apodíctico, de los diversos programas de gobierno.

La pregunta discreta es cuántos leerán y cómo leerán estos programas de gobierno. Sin ser muy negativos podemos. suponer que el número de lectores es bien reducido y concentrado en las cúpulas superiores de los propios partidos. Sin duda estas minorías se leerán a sí mismas. Si curiosean los programas de otras fracciones será con la intención de complementar las propias proclamas, porque a la hora de prometer nadie quiere quedarse atrás. De acuerdo a las encuestas de opinión pública, la mayoría de electores se ha sentido supersaturada con la propaganda vertida en los medios de comunicación, traduciendo incluso el gasto multimillonario en posibles centros de salud. $Y$ otra mayoría, mayor o más mayor, afirma que todos prometen mucho y muy pocos lo cumplen. 
¿Cuál es entonces la utilidad de estos densos programas de gobierno? La respuesta no es una ecuación matemática, sino una hipótesis en espera de prueba. Hay partidos contendientes que se sucedieron en el poder en las tres décadas pasadas y sus caras son conocidas al elector. Aquí entran en juego su publicidad y su historia, más que su crítica a los otros partidos. Si el elector se guía por la razón, fácilmente descubrirá que vuelven a prometer lo que nunca hicieron, incluso lo que se negaron a hacer en nombre de Dios y de la Constitución. La duda del elector puede brotar de dos fuentes: la voluntad de cumplir y la capacidad material de cumplir en determinados partidos políticos. No basta la buena voluntad de querer cumplir; es necesario ponderar si cuentan con el cuerpo de miembros honrados y competentes para poder ejecutar lo prometido. Por supuesto que si no hay voluntad de cumplir salen sobrando los técnicos ejecutores.

Pese a todas estas sumas y restas, los programas de gobierno tienen una gran importancia. Partiendo de una amplia variedad de promesas y de críticas terminan diseñando un esquema de plan económico y social. Este es un aspecto importante para enmarcar la continuidad y el cambio respecto al actual programa económico. Desde otro horizonte, propio de institutos académicos y de investigación, se han presentado algunos programas de consenso para el desarrollo económico-social, que conjugan la crítica equilibrada del actual modelo con las propuestas de nuevos pilares, áreas prioritarias y medidas macroeconómicas y sectoriales a integrar en el próximo quinquenio. Sin duda estos análisis y recomendaciones conllevan cierta expresión técnica, pero sirven de base fundamentada para responder a las demandas populares expresadas en forma sencilla. El o los partidos encuentran aquí una brújula orientadora.

Adicionalmente, puesto que algún partido ascenderá al poder, su denso programa de gobierno será utilizado, en ese momento, por los grupos de oposición - dentro y fuera de la Asamblea Legislativa- para recordarle y reclamarle todo lo que prometió hacer en la fase preelectoral. Para el partido gobernante su programa de gobierno será su agenda de trabajo y para las fracciones opositoras su agenda de presiones y reclamos. De ahí la importancia de prometer lo que se quiere y puede cumplir para no pasar a la 
historia con números rojos. El gran éxito de las elecciones sería leer la historia futura a partir de la historia presente.

\section{IIIo. CUAL ES EL PAPEI DEL GOBIERNO?}

Vistas las promesas de los partidos y las expectativas de los votantes, el primero que puede plantearse esta pregunta es el propio Gobierno. Si analizamos las proclamas de los partidos todos prometen hacer serias reformas en el orden político, jurídico, legal, social, económico, ecológico, cultural, familiar, sin olvidar la infancia, la mujer y la tercera edad. Parecería que el Gobierno es el omnipresente en todas las esferas de la convivencia social. En el otro extremo del péndulo se predica el papel subsidiario o supletorio del Estado quien, a primera vista, quedaría relegado a una función de servidumbre del sector privado. Conviene que entre todos lleguemos a un cierto consenso sobre las funciones $y$ responsabilidades del Estado, porque de acuerdo a sus funciones serán las cualidades exigidas, el número y la misma localización geográfica de las instituciones públicas, así como los requisitos de formación-promoción propios de la ley civil. Uno de los documentos esclarecedores son los acuerdos de paz, de los cuales emanan importantes conclusiones pactadas.

Ha sido un gran avance, una vez terminada la guerra, dejar bien esclarecido cuál es la función de quien fuera un superpoder dentro del Estado, la fuerza armada, y cuáles las funciones de la nueva policía nacional civil. Es claro que esta determinación debe ir modificando el número, las cualificaciones, las responsabilidades, la distribución geográfica y el mismo presupuesto asignado a la defensa territorial y al servicio de la seguridad interna de los ciudadanos. Aquí el principio de subsidiaridad se aplica de un modo justo y justiciero: poner fin a los escuadrones de la muerte y a todos los ilegalmente armados, privados y organizados. Cuanto mejor las fuerzas públicas cumplan sus funciones de defensa y de seguridad respectivamente, menos tendrán los privados que aplicar la justicia por cuenta propia, desacreditando la cultura de la paz.

Más difícil o no tan claro es determinar las funciones públicas en el orden legislativo y en la administración de justicia. La norma que nos dan los juristas, repetida en todas las proclamas políticas, 
es asentar un Estado de Derecho. Para los profanos, esto nos suena como una utopía, en su buen sentido: algo que no existe, pero que es la norma de lo que debe existir. Se parece a la recomendación de nuestros colegas economistas cuando hablan de lograr la plena estabilidad macroeconómica. Vengamos al Estado de Derecho, donde juega totalmente el principio de subsidiaridad. Es claro que los privados no legislamos, pero tenemos el derecho y el deber de elegir a los diputados más responsables y honestos entre las planillas presentadas. A su vez, ellos tienen el derecho, es decir el deber de representar la voluntad popular; este es su derecho de estado dentro de un Estado de Derecho. La contradicción surge cuando al interior de nuestras Asambleas Legislativas emergen mayorías y minorías que no coinciden y más bien se contraponen a las mayorías y minorías ciudadanas. No puede haber Estado de Derecho si tradicionalmente las mayorías parlamentarias legislan a favor de las minorías económicas, irrespetando el principio de subsidiaridad de las mayorías populares. No hay Estado de Derecho si los decretos emanan de acuerdo al número de manos alzadas y no tanto de acuerdo al bien común, que será tanto más bien común cuanto más favorezca a la mayor parte de la población. Quienes se mueven entre las bambalinas parlamentarias dicen que con frecuencia se arreglan pactos y alianzas poco decorosas, ajenas a los ideales proclamados y que desacreditan a ciertas fracciones "por unos dólares más". Quien ha dicho cosas más claras a este propósito ha sido el informe de la Comisión de la Verdad; por ello una menor mayoría le trabó la capucha de la ley de amnistía; pero el informe sigue respirando...

Difícilmente se puede hablar de Estado de Derecho si el órgano legislativo no es un poder compensador o recompensador de los poderes ejecutivo, judicial y militar. Este es uno de los problemas más álgidos que ha revelado el citado informe al sentenciar el delito y la culpabilidad institucional: no sólo los individuos sino las mismas instituciones delinquen. Directamente se integra aquí el órgano de la administración de justicia, donde hay que absolver de culpa a bastantes jueces y fiscales al hacer citatoria de toda la institución. La seriedad con que las gremiales de abogados y el Consejo Nacional de la Judicatura parecen haber realizado las postulaciones a la Corte Suprema de Justucia muestran que el in- 
forme de la Comisión de la Verdad no levantaba falsos testimonios. El principio de subsidiaridad tampoco fue el distintivo del órgano judicial; muchos culpables andan sueltos y muchos inocentes esperan estoicamente que rebusquen en el limbo de los juzgados el portafolio de su sentencia. Lo contradictorio de nuestro Estado de Derecho es que donde menos se habla del principio de subsidiaridad es donde más debe aplicarse: en el ámbito de la administración de justicia las mayorías populares esperan todo del Estado. Por sí mismas no tienen ningún poder; y el peor signo sería el poder de sublevarse porque esto indicaría que no existe un Estado de Derecho. No podemos hablar de un Estado de Derecho si, como en el pasado, los poderes jurídico y legislativo eran una servidumbre del estamento militar, alentado todo ello por los civiles influyentes. Es necesario que estas instituciones públicas se com. porten como poderes compensadores cuando una de ellas busca monopolizar el todo poder, y como instituciones recompensadoras cuando al unísono se busca el mayor bien común, el de las mayorías.

\section{IVo. EL ESTADO Y EL ORDEN ECONOMICO}

Sin lugar a dudas es en el orden y ordenamiento económico donde más se cuestiona y se crítica el papel del Estado. Utilizamos la palabra crítica en su sentido etimológico de analizar, enjuiciar y ponderar una acción o comportamiento individual o grupal. La sana crítica desemboca en evaluaciones y recomendaciones que, de acuerdo al caso, esclarecen la razón de dicho comportamiento o bien recomiendan correcciones y cambios de conducta. Se busca así la crítica constructiva. En nuestro tema esto suele ser algo difícil; los aprioris ideológicos, nacidos de la escolástica repetitiva y/o de la situación social del individuo o del grupo, fácilmente perturban el buen raciocinio y la crítica constructiva. La razón es bien sencilla: lo económico es el pan nuestro de cada día, la respuesta a las necesidades humanas para la supervivencia personal y familiar. Es normal que se busquen argumentos para situarse en uno u otro extremo del péndulo, olvidando que por donde más veces pasa el péndulo es por el punto medio. Como decían los antiguos: "in medio stat virtus", que lo traducimos en forma algo libre: desde el centro ponderemos los argumentos de ambos lados del péndulo. 
Si en los apartados anteriores esperamos una renovación interna y profunda de esas instituciones públicas para asentar un Estado de Derecho, la lógica de la argumentación no ha sido reduzcamos las funciones legales y judiciales del Estado, sino renovemos y cualifiquemos dichas instituciones para que ejerzan todas esas funciones en aras del mayor bien común. Se trata de una crítica constructiva. Viniendo a la esfera del quehacer económico partimos de una premisa fundamental: el proceso económico necesita un ordenamiento intersectorial en el tiempo y en el espacio. Sustituimos aquí el concepto de Estado de Derecho por la norma del ordenamiento económico, que encierra por lo menos tres grandes dimensiones.

\section{IV-1. La dimensión tiempo}

Los problemas y precariedades económicas presentes se generaron, utilizando el plural, en las décadas pasadas y no sólo en la última. La dimensión tiempo nos obliga a considerar y preparar el futuro, a sentar las bases del desarrollo para el próximo quinquenio. Esta primera connotación nos recuerda que los problemas económicos nacionales vienen y van en el largo plazo, que son problemas estructurales; incluso, bien usada la palabra, son problemas coyunturales que, en su origen latino (cum-iunctura), significa que el futuro será una conjunción de todas las acciones presentes. Por lo tanto los problemas económicos nacionales exigen analistas y análisis técnicos de parte de las instituciones públicas. Al ser problemas nacionales son problemas públicos, más difícilmente perceptibles por individuos, incluso por grupos privados, adscritos a este o aquel sector productivo. El laissez-faire no ha logrado amainar el historial de los ciclos económicos y cuando han arreciado las tormentas se le pide al Estado que lance los salvavidas. Por lo tanto, en las instituciones económicas, ministerios y similares, se requiere una consistencia, renovada y renovadora, de equipos técnicos especializados. Por desgracia, sucede frecuentemente que a cada cambio de gobierno, se desbaratan los equipos técnicos, se reemplazan por arribistas partisanos, logrando que los ciclos políticos desmembren la consistencia técnica y arrebaten al Estado su gran función de ser eficiente en la "cosa-pública" (res-publica). El gobierno se convierte así en el peor enemigo del Estado. Admitida 
esta fragilidad, desde la dimensión tiempo deducimos que la consistencia técnica pública no puede ser reemplazada por una sumatoria de decisiones privadas sectoriales, porque lo público es global e intersectorial. Correríamos el peligro de estar mal gobernados y mal administrados.

\section{IVo-2.-El entorno espacial}

La segunda dimensión es el entorno espacial. Todos estamos de acuerdo en afirmar que las economías, y más la nuestra, son abiertas y dependientes; baste leer las series estadísticas de nuestras balanzas comercial, corriente y general de pagos. Estamos de acuerdo en reconocer que si la adversa coyuntura internacional viene afectando los montos y valores de nuestras exportaciones-importaciones, también han sido los flujos externos de las remesas familiares, préstamos y donaciones quienes mantienen a flote nuestra economía por encima del nivel alcanzado con la productividad y recursos propios. En otras palabras, que el crecimiento quinquenal no es hijo legítimo de sólo el modelo, ni hermano gemelo del desarrollo económico. Es cierto que al terminar el siglo veinte se renueva en clave mayor la constitución de los grandes mercados comunes, de las nuevas trilaterales, de la globalización comercial, financiera y tecnológica. Al mismo tiempo también es cierto que, si miramos la geografía interna nacional y continental, observamos el problema de la globalización de la pobreza y de las necesidadas básicas insatisfechas. Ambos horizontes son parte de la misma unidad.

Los defensores del libre juego del mercado buscan una salida fácil al "concentrar el esfuerzo del Estado en lo normativo, en la atención de la pobreza y en la inversión de obras sociales". Al afirmar estas funciones no queda muy clara la premisa en que se basan: "Se pretende disminuir la participación directa del Estado en la generación de bienes y servicios, por razones de eficiencia económica". (FUSADES. La Prensa Gráfica; 12-03-94; p. 8). Decimos que no queda muy claro esto del principio de subsidiaridad del Estado si la globalización de la pobreza alcanza los dos tercios de la población, si las inversiones sociales y la inversión en capital humano son la base fundamental del crecimiento y del desarrollo económico. No queda muy claro si el Estado debe hacer poco o si 
debe hacer mucho. Por una parte se dice que hay que disminuir la participación directa del Estado en la generación de bienes y servicios "por razones de eficiencia económica", y por otra parte se le encomienda lo mayor y lo más difícil, "la atención a la pobreza y las inversiones sociales". Hay algo que no encaja en este principio de subsidiaridad: si el Estado es genéticamente ineficiente por qué se le encomiendan los servicios más numerosos, a más personas, los más difíciles y más deficitarios. Parecería que al Estado sólo se le encomiendan déficits fiscales para luego criticarlo. Sumando estas teorías con determinadas prácticas de privatización, el Estado se vería expoliado de ciertos servicios públicos que, bien administrados, aliviarían al erario en la misma manera que los privados pretenden mejorar sus propios erarios con tales servicios, fundados siempre en la congénita ineficiencia pública.

Aunque más adelante dedicamos un corto acápite al hábito de la culpabilización, merece la pena hacer un corto paréntesis. Esta postura ideológica se asienta en una premisa no bien fundamentada: el sector privado sí es eficiente y productivo. Esta premisa olvida que en pasadas décadas el sector privado se desarrolló sobre una amplia dotación de infraestructura física prestada por el Estado, junto con un elevado monto de subvenciones y exenciones, todo ello a cargo del erario público, sin la correspondiente prestación de los impuestos directos. Olvida que el sector privado creció dentro de un entorno proteccionista y concentrado que, a la larga, ha mermado su cualidad competitiva. Olvida que dicho crecimiento no ha corregido el desempleo estructural, no sólo coyuntural o estacional, forzando directa o indirectamente a que la administración pública se sobregire con un excedente de empleados públicos. Las migraciones de la población económicamente activa no sólo han ido del campo a la ciudad sino también hacia la administración pública. Entre los signos de desempleo estructural está el excedente de empleados públicos, no tanto por razones de prestigio social cuanto por motivos de misericordia social.

De una manera más fundamental, cómo se explica que la oferta de un sector tan productivo no haya creada la demanda nacional y que en tan largas décadas no haya dado una respuesta significativa a la resolución de la pobreza. Si tradicionalmente la pobreza no es un mercado para la economía de mercado no tiene mucho sen- 
tido presentarla como el modelo económico. La teoría debe confrontarse con la historia y ponderar las propias responsabilidades. Con ello el principio de subsidiaridad no contrae la actividad del Estado, sino que lo hace más responsable del mercado más amplio, más humano y más deficitario. Queda la pregunta de fondo, planteada al comentar el origen de nuestra guerra: de dónde nace la pobreza y quiénes son sus principales responsables?.- Sería muy triste para los teóricos de la economía de mercado que el propio modelo y el típico sector privado tengan arte y parte en la globalización de la pobreza y que luego se desproecupen del hijo de sus entrañas. Antes de teorizar sobre la ineficiencia del Estado, quienes trabajamos en el sector privado deberiamos someternos a un momento de autocrítica para evaluar cómo, desde el sector privado, estamos colaborando al proceso de erradicación sostenida de la pobreza. Más adelante volveremos a recordar que las universidades privadas tenemos una gran responsabilidadad en la gestación de teorías y en las propuestas técnicas a tal fin.

Tampoco es honesto recurrir a la citatoria de la corrupción pública, sin por ello disculparla, cuando existen múltiples modalidades de Fomiexport en el sector privado.Mas que amontonar ejemplos baste pensar que la inflación se alimenta de corrupción. Los contadores públicos pueden explicar cómo se forman los precios para subirlos y cómo se disminuyen los beneficios para reducir los impuestos. La enfermedad es más general; al fin y al cabo los residentes del sector público y del sector privado pertenecemos a la misma raza y cultura y queda por averiguar quién aprende de quién. En otras circunstancias no hubiera sido necesario hacer un paréntesis tan largo.

Volviendo a la dimensión geográfica de la función pública nos aproximamos desde otro ángulo a los requerimientos técnicos de estas instituciones, junto con el requisito del compromiso social. Estas instituciones deben equilibrar su gobierno hacia fuera y hacia dentro de la economía nacional. Una vez más aparece el requisito de los equipos técnicos. Las negociaciones con instituciones financieras multinacionales, gubernamentales o privadas, las renegociaciones de la deuda externa demandan una consistencia de equipos técnicos, dadas las consecuencias para el desarrollo interno presente y futuro. En un entorno de gestación de merca- 
dos comunes y de más amplias zonas comerciales el Estado requiere de cuadros más técnicos que cualquier empresa privada. Al tecnificar sus cuadros se debilita la acusación de ineficiencia y esto tiene otra consecuencia positiva. Al hablar de estas funciones publicas no las desmembramos de todo el aporte que deben prestar los representantes de los sectores privados porque visualizamos una economía concertada, como lo proponemos más adelante. Lo que subrayamos es la integración de ambos sectores bajo la orientación y normativa de la administración pública por la transcendencia social de estas negociaciones internacionales.

Contemplando las funciones del ordenamiento económico, propias del Estado, desde la dimensión tiempo (largo plazo) y espacio (mercado interno y externo) el requisito técnico debe estar acompañado del presupuesto compromiso social. En el último quinquenio hemos asistido a una desdichada esgrima entre tecnócratas y populistas (tales eran los calificativos), que de una $\mathbf{u}$ otra forma reaparece en el proceso preelectoral. Los buenos equilibrios macroecónomicos deben traducirse en los equilibrios microeconómicos de la equidad y transformación productiva. La técnica debe matrimoniarse con la misericordia social. A este respecto es esclarecedor y muy práctico en sus aplicaciones el concepto desarrollado por Roberto Rubio: la política mesoeconómica como puente que ensambla y reacomoda los avances macroeconómicos y las necesarias respuestas microeconómicas. Recomendamos esta lectura, en las publicaciones de FUNDE (febrero-1994).

\section{IV-3.- La integración económica}

Esto nos acerca a una tercera dimensión en las funciones del sector público, cual es el ordenamiento intersectorial o integración económica. Cuando hablamos de mercado estamos simplificando una realidad económica estructurada por múltiples ramas o sectores productivos mutuamente relacionados o más bien faltos tradicionalmente de la posible estructuración. Es interesante que en algunas propuestas de los partidos políticos aparezca esta preocupación. Importante también que a fines de 1993 el Banco Central haya publicado la matriz insumo-producto-1990 como parte del "Nuevo Sistema de Cuentas Nacionales". Entre los estudios disponibles han sido el Instituto de Investigaciones Económicas y Socia- 
les (IIES-UCA), los citados trabajos de FUNDE y de manera más detallada la "Propuesta de un programa económico y social de consenso para El Salvador", elaborado por CENITEC, quienes mejor desarrollan esta dimensión del proceso económico y la subsiguiente función del Estado.

Hay un presupuesto económico racional que hace depender el crecimiento interno de la mayor o menor integración de las diversas ramas productivas. La estructuración del aparato productivo distingue a los países desarrollados de los menos desarrollados. En vez de detenernos en algo que es obvio baste recordar algunas anécdotas. El iniciador de las matrices intersectoriales y premio Nobel, W. Leontief, de origen ruso, trabajó en la década de los 1920 en la elaboración de los cuadros de "balances-eslabones" que, en las primeras etapas de la planificación soviética, servirían a programar un crecimiento armónico de los diversos sectores (eslabones) de la cadena productiva. La intención técnica era lograr un crecimiento armónico. Perfeccionado el sistema de balances con las matrices insumo-producto, que W. Leontief desarrolló en los Estados Unidos, este instrumento de la contabilidad nacional será ampliamente utilizado en Europa occidental, en las décadas de la reconstrucción y auge económico, a modo de carta de navegación de los sectores productivos orientados por el Estado.

En la mente de W.Leontief había una gran intención: que las matrices intersectoriales sirvieran a los países pobres para lanzar sendas de desarrollo. Los países pobres, dirá él, con frecuencia son pobres no por falta de recursos sino por ignorar el modo de combinarlos. En El Salvador disponemos de dos matrices insumo-producto: 1978 (publicada en 1986) y 1990 (publicada en 1993). Sería un fuerte costo de oportunidad que este buen trabajo del Banco Central y técnicos de las Naciones Unidas quedara sin utilización práctica de parte del resto de instituciones públicas y de los representantes o gremiales de los sectores privados. Las matrices intersectoriales son un instrumento privilegiado para el diálogo concertado entre las dependencias del sector público y los representantes de los sectores privados tal como ha sido utilizado en la reconstrucción de la Europa occidental 


\section{IV-4.- Economía concertada}

Nuestra intención es relacionar la requerida integración económica con la función orientadora e integradora del Estado, en otras palabras con una economía concertada o de planificación indicativa. En el programa-CENITEC se puntualiza como primer objetivo: "Sentar las bases para la construcción en el mediano plazo de una economía integrada, moderna y diversificada". (p. 10). La siguiente explicación es fácilmente observable con un breve análisis de nuestras matrices 1978 y 1990.

"Actualmente la economía salvadoreña se caracteriza por su bajo nivel de productividad global y por las enormes diferencias de productividad entre sectores, por falta de integración vertical y horizontal, por la marcada especialización en la producción primaria y por la consecuente vulnerabilidad externa. En tales condiciones, es irreal pensar que es posible integrarnos a la economía mundial y regional de una manera eficiente. Además, con tales características es prácticamente imposible superar en un plazo razonable los graves problemas sociales que hoy nos aquejan. Por lo anterior hay que plantearse desde ya el objetivo de construir en el mediano plazo una economía diversificada tanto en la estructura de producción como en el destino de la misma, e integrada en el sentido de que existan enlaces productivos entre los diferentes sectores. Sólo de esta manera el país podrá enfrentar con éxito los grandes desafíos del siglo veintiuno". (p. 11)

Como primer objetivo," la integración de la economía nacional" pasa a ser el primer pilar del nuevo modelo. "En nuestra opinión, la integración de la economía nacional debe ser el primer pilar sobre el cual descanse un nuevo modelo de desarrollo, ya que sólo a partir de tal integración es posible avanzar hacia una modernización productiva y lograr una reinserción eficiente y dinámica en la economía internacional. En efecto, sólo si construimos una economía que se caracterice por su alto grado de integración y por su gran diversificación, tanto en la estructura de la producción como en el destino de la misma, podremos elevar los niveles de productividad global y aprovechar de manera eficiente los escasos recursos disponibles". (p. 13)

CENITEC quiere evitar equívocos y marcar bien las distincio- 
nes. "Debemos señalar que este pilar diferencia radicalmente el modelo que estamos proponiendo de los modelos que se han practicado hasta hoy, los cuales en lugar de buscar una integración de la economía nacional, provocaron de manera deliberada una desintegración de la estructura productiva del país." (p. 13).

En los programas económicos de los institutos de investigación el proceso de integración sectorial va unido al objetivo de "la transformación-reconversión sistemática del aparato productivo nacional" (IIES-UCA), a "la consolidación de un nuevo eje exportador" y a "la integración centroamericana" (CENITEC). Aunque no sean éstas las únicas reestructuraciones requeridas en nuestra economía, sirven como botón de muestra para legitimar las amplias funciones cualitativas y cuantitativas que pasan a ser responsabilidad del Estado. Los institutos de investigación coinciden en la enumeración de funciones, extendiéndose con mayor o menor amplitud en su explicación.

CENITEC recomienda la "Renovación del papel del Estado" a quien competen cuatro funciones básicas:a) la función de mantenimiento de la estabilidad financiera y cambiaria; b) la función ordenadora y reguladora; c) la función integradora, y d) la función redistributiva. (p. 15). El IIES-UCA, que desde 1991 había asignado similares funciones al Estado, subraya el papel promotor $y$ orientador en todo el proceso de la reconversión productiva y tecnológica, siendo necesario para ello un Estado moderno y modernizante. (Realidad Económica y Social. 1991; No. 21; pp. 404419). Tanto el IIES como CENITEC amplían la función redistributiva del Estado ( políticas distributivas, redistributivas y selectivas de desarrollo), así como las aplicaciones concretas de la política social del Estado. (p. 23)

Alfonso Goitia, en su conferencia sobre "La modernización del Estado:el papel del Estado en la sociedad", adjudica a "una administración pública eficiente" las funciones de un Estado orientadorregulador, responsable en los social, promotor de la participación y la concertación, redistribuidor de los ingresos y de la riqueza, promotor de la descentralización y orientador en el marco de la inserción internacional. (FUNDE; febrero 1994).

En su resumen de la estrategia económica 1994-1999 FUSADES 
,desde su perspectiva de economía de mercado y bajo el epígrafe de "modernización del Estado", le asigna funciones nominalmente similares. Partiendo del presupuesto de un Estado conformado por cuadros profesionales, idóneos y capacitados, sus funciones vienen enmarcadas en la eficiencia: el Estado como regulador eficiente, como servidor eficiente, como empleador eficiente, como inversionista eficiente, como distribuidor (no se adjunta el calificativo de eficiente) y como promotor de acuerdos comerciales. Página siguiente, aparece el combate por la disminución de la pobreza, la inversión en capital humano, la priorización del gasto social.

Aunque las filosofías subyacentes a estos institutos de investigación difieran sensiblemente, por lo menos coinciden nominalmente en las nuevas y crecientes funciones y responsabilidades del Estado. Hay una central coincidencia en proponer, recomendar y exigir un Estado modernizante, eficiente y más descentralizado. Situados en una etapa de reconstrucción nacional también el sector privado debe someterse a un momento de autocrítica, si desea avanzar en la línea de la modernización, de la eficiencia productiva y de su integración económica. En este proceso la presencia del Estado no debe limitarse a un papel subsidiario porque la reconstrucción nacional requiere el ejercicio de ese conjunto de funciones que los institutos de investigación coinciden en asignarle.

Estamos hablando de reconstrucción nacional y de economía concertada, sinceramente con la sensación de que simplificamos el objetivo (reconstrucción nacional y el método (economía concertada). El entorno electoral, precedido por los dos años que nos distancian de los acuerdos de paz, parecerían presentar serios obstáculos tanto a este objetivo como a este método de la concertación. No sólo hay trabas económicas para resolver los problemas económicos, sino comportamientos culturales, políticos, partidistas que entorpecen este caminar. Ha sido todo el proceso de la propaganda electoral lo que motiva el siguiente paréntesis que, a primera vista, estaría fuera de lugar.

\section{Vo.- LA CULPABILIZACION; UN MAL PARENTESIS}

Tal vez el término culpabilización no aparece en el diccionario 
de la lengua, pero sí está presente y actuante en la realidad pre y postelectoral. En el diccionario sí aparece el término culpabilidad, pero no tanto en el comportamiento político y social. Culpabilización es el arte congénito de echar la culpa de todo a los demás, con lo cual el sentimiento de culpa y culpabilidad propia se convierten en conductas inexistentes. Las mayores energías y la más aguda inventiva se transforman en acusaciones, mientras que la verdad sigue siendo la gran víctima de la culpabilización. Los acuerdos de paz se pactaron como un puente hacia el descubrimiento de la culpabilidad, pero los hemos transformado en un instrumento de la culpabilización; si los pactos y el calendario no se cumplen la culpabilidad está en los otros. El informe de la Comisión de la Verdad también ha sido otro vehículo de la culpabilización, para unos por lo que dijo y para otros por lo que dejó de decir. Con la ley de amnistía se decreta la culpabilización por omisión; nadie o muy pocos se declaran culpables y la consigna de perdón y olvido se transforma en olvido del perdón. El Foro de Concertación Económica y Social ha sido otro prolongado ejercicio de la culpabilización. Acusamos pero no nos acusamos.

Con el proceso electoral se magnifica el hábito de la culpabilización como estrategia para alcanzar el poder. El partido de turno culpabiliza al anterior, así como éste lo hizo con su predecesor y todas las fracciones contendientes afilan su lápiz con la misma intención. El hecho de que proliferen tantas camisetas, con sus escudos policromados, significa que nos revestimos con el hábito de la mutua culpabilización. La guerra, el partidismo político y el proceso electoral han deteriorado la capacidad de autorreflexión, de autocrítica, de integración de ánimos cuando estamos en una etapa de reconstrucción. La culpabilización, en cuanto prolongación de una guerra civil hablada, debilita la capacidad para reponernos de los daños causados por la guerra armada. La culpabilización mantiene la agresividad y crea nuevas formas de agresividad, delincuencia y maras... La culpabilización nos inhibe para ver algo bueno en los demás, individuos, grupos, instituciones, y nos embota la conciencia para reconocer los propios errores. Ante la publicidad de ciertos políticos uno se pregunta si realmente creerán lo que están prometiendo, porque la culpabilización es atrevida hasta para mentir. La culpabilización 
no deja medrar el verdadero pluralismo, el parlamentarismo, la sana coexistencia de ideologías y socava la gobernabilidad.

La culpabilización es un mal paréntesis de postguerra y de transición electoral en un país rico en contradicciones sociales. Por ello es necesario que este paréntesis no se convierta en tesis prolongada. Si en todos los órdenes de la convivencia social se ha ejercitado la culpabilización, incluido el plano religioso, sin duda es en el ordenamiento económico donde la animadversión se traduce en reclamos y acusaciones mayores. El hecho mismo de que todas las proclamas partidistas se comprometan con la erradicación sostenida de la pobreza es una declaración patente de un hecho de culpabilidad generalizada, que no deja espacio a la culpabilización. Tampoco nos exime de la propia culpabilidad transferir la culpabilización a las exigencias del modelo económico, como fríamente lo hacen algunos grupos y escuelas teóricas. A los modelos $\mathrm{y}$ a los árboles se les conoce por sus frutos.

No todo es negativo en este proceso de culpabilización, que por lo menos consagra la culpabilidad anónima. Hay algo que funciona mal, y esto se repite en cada fase electoral. Baste recordar la extensión y el detalle de las proclamas partidistas, cuyo valor no está tanto en lo que prometen, sino en las fallas y atascos que descubren. Parecería que una vía de solución fuese un proceso de elecciones prolongadas, donde el hábito de culpabilización propio de esta época se transformara en un hábito de vigilancia,control y coparticipación para alcanzar lo prometido en el momento electoral. De poco servirían unas elecciones donde se vierten todas las energías como en una carrera de cien metros con vallas, cuando el proceso de economía concertada para la reconstrucción nacional se asemeja más a un marathon de muchos kilómetros. $\mathrm{Si}$ a las presentes se las ha llamado las elecciones del siglo, la dimensión tiempo, la constancia y la perseverancia en gobernantes y gobernados debe marcar el próximo quinquenio. La gobernabilidad funciona mejor si hay co-gobernabilidad, lo cual supone la colaboración de los gobernados y la apertura a la colaboración en los gobernantes.

\section{VIo.-HACIA LA CO-GOBERNABILIDAD}

No significa que va a haber dos gobiernos sino que las nuevas funciones y las nuevas dificultades económico-sociales, ya previsi- 
bles, requieren que "el nuevo gobierno asuma estratégicamente la búsqueda del consenso como la fórmula fundamental para la toma de decisiones, sin que esto signifique el establecimiento de un cogobierno". (CENITEC. La Prensa Gráfica; 4-marzo-94; p. 27). En la misma página, de cara el gobierno que pudiera salir electo, CENITEC presenta un conjunto de factores,internos y externos, que han posibilitado el reciente crecimiento económico, algunos de los cuales previsiblemente disminuirán su impacto en el futuro al mismo tiempo que suben los reclamos por el cumplimiento de los acuerdos de paz y por la satisfacción de las crecientes demandas sociales. En este sentido decimos que la gobernabilidad se hace entre todos. Hay que sostener y fortalecer toda la experiencia metodológica adquirida con los acuerdos de paz: diálogo, concertación, integración de distintos y opuestos, grupos de apoyo, como valores adquiridos y como fuerzas compensadoras frente al mal hábito de la culpabiliżación. CENITEC acaba su página con una recomendación concreta. "Finalmente se requiere formar un gabinete competente y en la medida de lo posible pluralista, que tenga la credibilidad necesaria para implementar la política económica diseñada".

Por estar a favor de las amplias y nuevas responsabilidades del Estado recomendamos que el Estado orientador se deje orientar y busque la mejor colaboración. Esto equivale a decir que las elecciones no son un acto sino un proceso concertado. Si revisamos las funciones que los institutos de investigación asignan al Estado veremos que son responsabilidades públicas, sociales y democráticas, y por lo tanto deben administrarse con las mismas características. El gobierno que ahora deja el poder se adhirió nominalmente al principio de subsidiaridad, pero su comportamiento político ha sido autoritario y antidemocrático. No hay contradicción entre mayores responsabilidades y más democracia.

Hay un detalle, que no significa aquí cosa pèqueña, sino un compromiso concreto para el nuevo gobierno: el cumplimiento de los puntos y calendario aún pendientes de los acuerdos de paz. No es por capricho que el Secretario General de las Naciones Unidas y el mismo gobierno de los Estados Unidos fuercen a tal cumplimiento, condicionando incluso parte de la ayuda programada. El cumplimiento de estos pactos afecta a amplios grupos popula- 
res, organizados y no organizados, a quienes el gobierno deberá escuchar y atender por bien de su propia estabilidad. Otra puerta de la apertura democrática se abre en la prosecución del Foro de Concertación Económica y Social, donde la toma de conciencia de las representaciones laborales seguirá presentando justa batalla a las gremiales patronales y el mismo gobierno. También aquí se juega la estabilidad del próximo gobierno, sin caer en la tentación de recurrir a los antimotines. Es difícil dar marcha atrás en el camino avanzado porque también la iglesia y algunas iglesias seguirán siendo fermento de la conciencia democrática. De acuerdo a cómo se vislumbran los resultados electorales de final de abril, el nuevo gobierno deberá abandonar el lema de "los arrollaremos" por la consigna de los escucharemos, de acuerdo a su propaganda electoral.

Al diálogo político-social se añade la concertación económica donde el Estado adquiere grandes funciones. Hay un deseo unánime de que el Estado esté conformado por cuadros técnicos, honestos y socialmente comprometidos. Pero, también a ellos les acecha un peligro, sobre todo si están sometidos a presiones políticas: el síndrome de la autosuficiencia y el del top-secret. Los asuntos públicos deben publicitarse, de suerte que institutos de investigación y universidades, preocupadas por la realidad nacional, avancen desde la información a la propuesta de alternativas posibles." El logro de dicha gobernabilidad supone definir con absoluta claridad las reglas del juego que regirán en el plano económico-social durante los próximos años; particularmente se necesita definir lo más rápido posible cuál será el manejo futuro de la política económica en aquellas áreas consideradas críticas por el sector empresarial y por el sector laboral. Sólo de esta manera será posible generar la confianza para aumentar las expectativas de inversión y asegurar la estabilidad política. Por otra parte, el logro de la gobernabilidad supone llegar a acuerdos básicos con los sectores económicos y sociales del país sobre la distribución de los costos y beneficios resultantes de la aplicación de la política económica..."

Durante el proceso electoral han ocupado las primeras páginas las cúpulas de los partidos contendientes, como es de esperar los sigan haciendo al interior de la Asamblea Legislativa. Concluidos estos eventos es necesario que los institutos de investigación y las 
universidades comprometidas coparticipen en el proceso de la economía concertada. De hecho, desde estas instituciones han emanado programas alternativos de desarrollo económico; su función es ser compañeros de viaje y orientadores de la realidad nacional. Si los cuadros técnicos de la administración pública emanan frecuentemente de estas institutuciones académicas, una sana concertación aconseja que se mantengan abiertos estos vasos comunicantes. Esta intercomunicación es necesaria en todo el proceso de la transformación tecnológica y reconversión productiva, siempre en comunicación con el sector privado formal e informal. Pero, sin duda el papel de estas instituciones académicas será el de mantener viva la llama del compromiso social en los poderes públicos.

A este respecto hay que decir que más universidades no ha significado más universidad. En general, la presencia activa universitaria ha sido lánguida por lo que hace a los aportes técnicos y sobre todo en el compromiso social. Incluso la ley de educación superior espera la resurrección en el sepulcro de la Asamblea Legislativa. Debiendo ser voz de los sin voz en el orden académico y en la misericordia social nos hemos podido convertir en la voz sin sonido. Si escribimos para los demás también debemos autoevaluar nuestra modernización, eficiencia y compromiso. Precisamente, en la fase postelectoral, cuando languidece la actividad partidista, reaparece la función insustituible de hacer cultura universitaria dentro y fuera de las instituciones académicas. La reconstrucción nacional, los acuerdos de paz y las promesas sociales nos integran en este quehacer común.

En el proceso electoral, por concluir, aparece un dato significativo: ningún partido ha obtenido la mayoría absoluta para adjudicarse la representación monopólica del sentimiento y esperanzas ciudadanas. Otro dato significativo es que los problemas económico-sociales van a más y han generado mayores promesas con mayores expectativas. Un gobierno, relativamente minoritario, no será capaz - por sí sólo - de dar respuesta a los problemas, promesas y expectativas. Por ser ellos y ellas tan grandes, creemos que las funciones y responsabilidades estatales crecen en la misma medida, así como crece la necesidad de solicitar la mejor colaboración. No es al Estado el único a quien le pidamos eficiencia y modernización, ni tampoco que se haga a un lado. 
Dos o tres posturas son posibles. La primera que, pese a su situación relativamente minoritaria, el nuevo gobierno se adjudique la prepotencia del todo poder y del todo saber. En tal hipótesis, vencería pero no convencería y de menos a más iría perdiendo credibilidad. Esta postura generaría la crítica negativa, la animadversión y el entorpecimiento no sólo de la oposición partidista,sino de las terceras fuerzas sociales e instituciones académicas. La pérdida de credibilidad se transformaría en degeneración económica y conflictividad política.

Parecería, simplificando, que la postura racional, la gobernabilidad requiere una acción concertada, una búsqueda de consenso nacional. Ello requiere un cambio de cultura en gobernantes y gobernados. Las tensiones partidistas emergen naturalmente en los períodos electorales y con ellos los problems a resolver. Pasada esta fase, el partidismo y el pluralismo ideológico debieran evolucionar hacia la crítica constructiva que es más activa y sobre todo más creativa en aras de la reconstrucción nacional. Esta es una nueva responsabilidad del Estado: ayudar a ser ayudado. Aquí tienen su papel el Estado, las terceras fuerzas sociales y las instituciones académicas. Hay un tiempo para dividir y hay un tiempo para juntar, hay un tiempo para criticar y hay más tiempo para construir. 